\title{
Therapeutic communication in nursing students: A Walker \& Avant concept analysis
}

\author{
Mahbobeh Abdolrahimi ${ }^{1}$, Shahrzad Ghiyasvandian², Masoumeh Zakerimoghadam ${ }^{3}$, Abbas Ebadi $^{4}$
}

${ }^{1}$ Ph.D. Candidate of Nursing, Department of Medical Surgical Nursing, Faculty of Nursing and Midwifery, Tehran University of Medical Sciences, Tehran, Iran

${ }^{2}$ Associate Professor, Department of Medical Surgical Nursing, Faculty of Nursing and Midwifery, Tehran University of Medical Sciences, Tehran, Iran

${ }^{3}$ Assistant Professor, Department of Critical Care Nursing, Faculty of Nursing and Midwifery, Tehran University of Medical Sciences, Tehran, Iran

${ }^{4}$ Associate Professor, Behavioral Sciences Research Center, Nursing Faculty, Baqiyatallah University of Medical Sciences, Tehran, Iran

Type of article: Review

\begin{abstract}
Background and aim: Therapeutic communication, the fundamental component of nursing, is a complex concept. Furthermore, the poor encounters between nursing student and patient demonstrate the necessity of instruction regarding therapeutic communication. The aim of this study was to define and clarify this important concept for including this subject in the nursing curriculum with more emphasis.

Methods: A literature search was conducted using keywords such as "nursing student", "patient" and "therapeutic communication" and Persian-equivalent words in Persian databases (including Magiran and Medlib) and English databases (including PubMed, ScienceDirect, Scopus and ProQuest) without time limitation. After extracting concept definitions and determining characteristic features, therapeutic communication in nursing students was defined. Then, sample cases, antecedents, consequences and empirical referents of concept were determined.

Results: After assessing 30 articles, therapeutic communication defining attributes were as follows: "an important means in building interpersonal relationships", "a process of information transmission", "an important clinical competency", "a structure with two different sections" and "a significant tool in patient centered care". Furthermore, theoretical and clinical education and receiving educators' feedback regarding therapeutic communication were considered as antecedents of the concept. Improving physical and psychological health status of patient as well as professional development of nursing students were identified as consequences of the concept.

Conclusion: Nursing instructors can use these results in order to teach and evaluate therapeutic communication in nursing students and train qualified nurses. Also, nursing students may apply the results to improve the quality of their interactions with patients, perform their various duties and meet patients' diverse needs.

Keywords: Communication, Nursing, Students, Patients
\end{abstract}

\section{Introduction}

Ethics, the principles and moral norms that control human behavior and decision making, is a basic requirement in today's modern world which has many benefits in our social and professional life (1). Adhering to ethical codes is essential to healthcare providers because they care for different patients with unique characteristics and needs (2). Therefore, nurses, as the largest branch of healthcare providers, are required to have regard to ethical standards for delivering care professionally in various fields (3). Furthermore, the Medical Ethics Committee of the Academy of Medical Sciences of the Islamic Republic of Iran, as well as the Nursing Organization revised ethical codes during two years and considered ethical codes as an educational credit in the nursing curriculum (4). One of the most significant sections of ethical behavior is communication $(2,4)$. Communication is a complicated phenomenon with

\section{Corresponding author:}

Associate Professor Dr. Shahrzad Ghiyasvandian, Department of Medical Surgical Nursing, Faculty of Nursing and Midwifery, Tehran University of Medical Sciences, Tehran, Iran. Tel: +98.66927171, Email: shghiyas@tums.ac.ir Received: November 14, 2016, Accepted: March 16, 2017, Published: August 2017 iThenticate screening: March 18, 2017, English editing: May 23, 2017, Quality control: June 28, 2017

(C) 2017 The Authors. This is an open access article under the terms of the Creative Commons Attribution-NonCommercialNoDerivs License, which permits use and distribution in any medium, provided the original work is properly cited, the use is non-commercial and no modifications or adaptations are made. 
different types that plays an important role in providing ethical care $(5,6)$. The main type of communication, therapeutic communication between healthcare provider and patient, is an important subject in nursing literature (79). Although this subject is an old one, recent advances in the field of healthcare and patient centered care approach, has increased therapeutic communication importance $(10,11)$. Furthermore, this concept is considered in the charter of patients' rights to gain patient cooperation (11). Nursing students who will become future nurses should establish effective interactions with patients to deliver holistic and quality care (12). But, many studies in Asian countries like Iran and china and some European countries such as the United Kingdom and even the USA have shown the inadequacy of therapeutic communication between nursing students and patients (13-22). The short period of time that nurses and nursing students spend during their superficial relationship with the patient is often limited to decreasing physical problems and not providing psychological care $(21,23)$. Nursing students considered therapeutic communication as one of the most stressful tasks in replacements $(24,25)$. Moreover, bachelor nursing students declared the decreasing level of therapeutic communication during their study course and they consider it as one of the least important components of nursing $(20,26,30)$. Nursing student-patient interaction failure leads to misinterpretation of information and patient damage which reduces nursing care quality as well as patient satisfaction, and creates a negative attitude in patients $(27,30,31)$. Furthermore, poor nursing student-patient encounters are associated with anxiety, depression, low self-esteem and lack of success in nursing students $(25,32)$. In different studies regarding nursing student and patient relations, some authors didn't provide a clear definition of therapeutic communication in nursing students and confined their work to explain its outcomes in patients or healthcare provider $(32,33)$. Also, researches regarding nursing student therapeutic communication with patients are limited (34). As therapeutic communication is a vague and multifactorial concept which has lots of benefits for both parties $(12,35,36)$, it is important that nursing educators search for ways to promote deep understanding of therapeutic communication in nursing students, and ensure that the nursing students are capable of establishing communication effectively with patients at the clinical rotations and after graduation (37-39). Therefore, the researchers decided to elucidate this concept by a proper concept development approach for answering research question: What is the definition of nursing student-patient therapeutic communication in various studies?

\section{Material and Methods}

\subsection{Concept analysis approach}

This study was conducted in 2017 by the Walker \& Avant concept analysis approach. The Walker \& Avant concept analysis is a useful approach to clarify complicated concepts, such as therapeutic communication. This approach includes eight different steps as follows: (1) selecting a concept; (2) determining the aim of analysis; (3) identifying all possible uses of the concept in nursing; (4) determining concept defining attributes; (5) identifying a model case; (6) identifying a borderline and a negative case; (7) identifying antecedents and consequences of the concept; and (8) defining empirical referents of the concept (40).

\subsection{Data sources}

For retrieving related articles, a review of literature was performed with combining, using the "AND" Boolean word, keywords such as "nursing student", "patient" and "therapeutic communication" in title or abstract, all full text articles published in scholarly journals in English databases (including PubMed, Science Direct, Scopus and ProQuest) were extracted without time limitation.

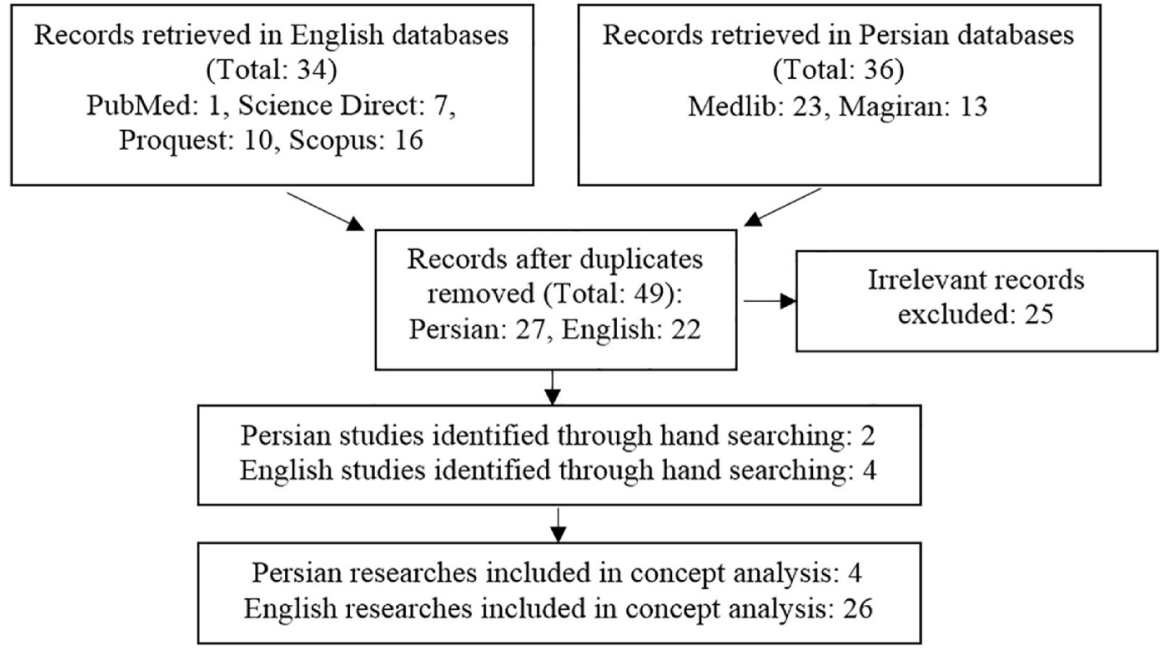

Figure 1. Main reporting points for literature review flowchart 
Also, full text articles published in main Persian databases (including Magiran and Medlib) were searched with equivalent Persian keywords. This search resulted in 70 articles. After removing duplicating records, 49 abstracts were studied and 25 irrelevant articles regarding clinical nursing were excluded. Furthermore, six articles were entered with a hand search. In total, 30 articles were entered in the study. Figure 1 shows the flowchart of main reporting points of this literature review.

\section{Results}

\subsection{Selecting a concept}

To perform a concept analysis according to the Walker \& Avant approach, the researchers should choose a complicated concept which plays an important role in the nursing career (40). Thus, the therapeutic communication concept was selected because it is the focal point of nursing care and it is highlighted in nursing standards of professional care (41). It is an old concept which is rooted in the Hippocrates principles of medicine (8). Also, therapeutic communication significance has improved in the last decade due to regulatory standards which highlight the role of patient education in order to respect patient autonomy in decision making (42).

\subsection{Determining the aim of analysis}

Therapeutic communication is a context based phenomenon which is affected by culture and language of involving people (35). So, researchers analyzed the nursing student-patient therapeutic communication concept by considering both Iranian and international articles to provide a better understanding of it.

\subsection{Identifying all possible uses of the concept in nursing}

Researchers identified all applications of the concept by reviewing the related literature (40). The word "therapeutic" refers to the art and practice of caring (7). The word communication is derived from the Latin word "Communicare" which means "making something public". During communication, the sender's thought, feeling and idea expand outward to the public in an interpersonal relationship. About 2,300 years ago, Aristotle defined communication as "applying all possibilities to persuade others" (43). Therapeutic communication in nursing is rooted in Florence Nightingale's writings in 1860 in which she considered therapeutic communication as the alphabet of caring through which a nurse can interpret every change in patient condition without conveying a word (16). After her, different nursing professional associations highlighted therapeutic communication as one of the most vital elements in nursing (22). Some studies have addressed therapeutic communication in nursing students. However, most of the authors have provided just implicit sentences as therapeutic communication definitions which are presented in Table 1.

\subsection{Determining concept defining attributes}

After determining all uses of nursing student-patient therapeutic communication and reviewing its various definitions, the researchers determined the concept characteristics (40). These attributes which present the most comprehensive vision of therapeutic communication and separate it from others are as follows: therapeutic communication as "an important means in building interpersonal relationships", "a process of information transmission", "an important clinical competency", "a structure with two different sections" and "a significant tool in patient centered care". Nursing students connect with patients and make a face to face interpersonal relationship through empathy and listening skills $(7,29,32-34,44-46,48,49,51,52,56,58,59,62,64,67)$. Applying nursing process during care provision, nursing students use therapeutic communication in order to assess patients' health state and educate them $(44-46,49,63,64)$. Nursing trainees need to acquire various clinical competencies, of which, one of the most important is therapeutic communication competence, which should be taught and evaluated in order to have competent nurses in the future $(34,47,49,50,56,57,67,68)$. To understand the complete meaning of messages, student nurses try to establish therapeutic communication with patients through nonverbal and verbal interactions $(34,46,49,50)$. Modern caring principles suggest that a patient, as a unique person and the main metaparadigm in nursing, should be cared for, based on patient-centered care standards $(7,29,44,46,60-62)$.

\subsection{Identifying a model case}

An example of the concept of interest which includes all defining attributes, is a model case (40). A model case of therapeutic communication is presented here: $\mathrm{Ms} \mathrm{Z}$ is a nursing student who likes nursing and interacts with patients even when her instructor does not evaluate her. When she goes to the patients' room, she greets all patients and introduces herself with suitable words and tone. She asks patients about their problems kindly and notices their reactions. She does her best to solve their problems and satisfy their needs. She studies books and asks instructors to improve her knowledge, and answers patients' questions. The patients perceive that she wants to help them. She is a 
calm nurse and she handles patients' bad behavior. She respects boundaries with patients but she accepts all her patients and listens to them. She knows her patients and respects their culture. She notices patient health literacy and she gives them feedback so that they understand her messages. She considers therapeutic communication as her professional and religious duty. When patients do not cooperate with her, she removes communication barriers and uses patients' companions. She takes patients' permission before doing procedures. Therefore, the patients trust her and tell her about their different needs.

\subsection{Identifying a borderline and a negative case}

A borderline case is similar to a model example, but it only possesses some of the defining attributes of the concept. The borderline case instability makes concept defining attributes more clear (40). A borderline case of concept of interest is presented here: Ms A is a nursing student who works part time in an educational hospital. She regards therapeutic communication and patient education as her duty and she tries to do her tasks but it is very hard for her to communicate with patients. She is tired because she has worked for a long time during night. Although she has clinical experience, she thinks that patients do not trust her during her clinical rotations as they have a fear of being her laboratory mice. So, she rarely communicates with patients and if patients don't answer her questions, she won't communicate with them any longer. She only does clinical procedures for them according to the physician's orders or she changes bad tempered patients with good tempered ones. She prefers female patients because she sometimes has problems with male patients. A negative case is an example of a case that doesn't demonstrate any defining attributes of the concept under analysis (40). A negative case of therapeutic communication is presented here: Ms B is a nursing student in the internship clinical rotation. At the beginning of her first clinical rotation she was too shy to interact with patients. Also, because of her lack of knowledge, it was too hard for her to provide patient education about activity and nutrition. Therefore, the patients didn't answer her and guarded against her. So, she could not accept her patients, and had quarrels with some of them. Now, as a senior nursing student, she has the knowledge to provide patient education but she doesn't answer the patients' questions because of her tiredness. So, she refers the patients to the doctors. She doesn't use the nursing student label and she doesn't introduce herself as a nursing student. She doesn't want to be a nurse in future. She only wants to spend her internship period to change her subject after graduation.

\subsection{Identifying antecedents and consequences of the concept}

Antecedents are incidents that must appear before the occurrence of concept of interest (40). Nursing student-patient therapeutic communication antecedents include education and clinical practice $(47,49,50,52,54,57,59,61,63$ 66). Through receiving educators' feedback during theoretical and clinical instruction, skills such as listening and empathy with respecting interpersonal boundaries are developed in nursing students $(7,29,33,34,45,48,50,52$, $56,59,64,67)$. Consequences are the results of occurrence of concept of interest (40). Nursing student-patient therapeutic communication consequences include patient's physical and psychological health growth and nursing student professional growth $(45,51,52,55,59,60,62-64)$.

\subsection{Defining empirical referents of the concept}

In the last step, researchers determined therapeutic communication empirical referents. This step facilitates measuring the concept of interest and demonstrates its existence and importance in the nursing profession (40). There are various checklists and questionnaires for measuring nursing student's and patient's therapeutic communication $(29,47,53,61,64)$. Rosenberg \& Gallo-Silver's tool was selected to investigate various empirical referents of concept (29). This instrument is a checklist for student self-evaluation and is consisted of 13 items and seven subscales as follows: welcoming the patient, showing empathy, providing encouragement, helping orient the patient, enhancing the patient's sense of self-control, responding to patient's cues and initiating nursing student and patient partnership. Some items that are related to the defining attributes of therapeutic communication were chosen from the instrument and presented in Table 2. 
Table 1. Definitions of nursing student-patient therapeutic communication

\begin{tabular}{|c|c|}
\hline $\begin{array}{l}\text { Ref. } \\
\text { no. }\end{array}$ & Definitions \\
\hline 44 & $\begin{array}{l}\text { During therapeutic communication process, nursing trainees use interpersonal skills such as listening for connecting } \\
\text { with patient, answering patients' questions correctly and providing patient centered care. }\end{array}$ \\
\hline 45 & $\begin{array}{l}\text { During process of conveying information, nursing students build interpersonal relationship with patient through } \\
\text { empathy, to solve patients' problems and meet their psychological and physical needs more comfortably. }\end{array}$ \\
\hline 46 & $\begin{array}{l}\text { It includes data transfer process using verbal and nonverbal communication through which the student and patient } \\
\text { relate and cooperate with each other comfortably. }\end{array}$ \\
\hline 47 & $\begin{array}{l}\text { Skill of therapeutic communication, a main clinical competence, improves through theoretical and clinical } \\
\text { education. }\end{array}$ \\
\hline 48 & $\begin{array}{l}\text { Therapeutic communication, including listening, is the most important skill in establishing interpersonal } \\
\text { relationship with patients in psychiatric wards. }\end{array}$ \\
\hline 33 & During therapeutic communication, a relationship is built between patient and student through empathy. \\
\hline 49 & $\begin{array}{l}\text { Therapeutic communication is a required and educable skill in establishing the process of interaction in which } \\
\text { information is transferred both verbally and non-verbally between nursing student and patient in competent nursing } \\
\text { practice. }\end{array}$ \\
\hline 50 & $\begin{array}{l}\text { Therapeutic communication techniques, combining verbal and nonverbal communication, is a paramount } \\
\text { competence in nursing practice which is improved in nursing trainees through receiving feedback during practice. }\end{array}$ \\
\hline 29 & $\begin{array}{l}\text { Therapeutic communication is a tool for providing holistic and patient centered care through respecting boundaries } \\
\text { and empathy. }\end{array}$ \\
\hline 51 & $\begin{array}{l}\text { When communication between nursing student and patient is to help patients to cope with problems and } \\
\text { unchangeable conditions it considers as the therapeutic communication. }\end{array}$ \\
\hline 52 & $\begin{array}{l}\text { They are skills or techniques that develop in nursing students through applying educational strategies and receiving } \\
\text { lecturer's feedback and are used to supply psychiatric patients with quality care. }\end{array}$ \\
\hline 7 & $\begin{array}{l}\text { Therapeutic communication is a tool for provision of healthcare through empathy and respecting interpersonal } \\
\text { boundaries. }\end{array}$ \\
\hline 32 & Nursing students apply therapeutic communication techniques to build a relationship with the patient. \\
\hline 53 & $\begin{array}{l}\text { They are communication techniques which should develop in nursing students through education and practice in } \\
\text { different clinical rotations. }\end{array}$ \\
\hline 54 & $\begin{array}{l}\text { Therapeutic communication includes a set of necessary clinical nursing skills which develop in nursing students } \\
\text { through clinical practice. }\end{array}$ \\
\hline 55 & $\begin{array}{l}\text { The practical skills of therapeutic communication as well as theoretical knowledge of communication are used } \\
\text { during nursing student-patient interaction which leads to improving healthcare quality. }\end{array}$ \\
\hline 56 & It is a required competence in building interpersonal relations between nursing student and patient through empathy. \\
\hline 57 & $\begin{array}{l}\text { Therapeutic communication is a teachable skill required to prepare students to provide competent and professional } \\
\text { care to the patient. }\end{array}$ \\
\hline 58 & $\begin{array}{l}\text { Communicating with a patient therapeutically is an essential skill in building interpersonal relationship between } \\
\text { patient and nursing students. }\end{array}$ \\
\hline 59 & $\begin{array}{l}\text { It is the main educable nursing skill which builds a healing relationship between nursing student and patient through } \\
\text { empathic dialogue that improves patient outcomes. }\end{array}$ \\
\hline 60 & $\begin{array}{l}\text { Therapeutic communication is an important part of nursing care which increases patients' participation in their care, } \\
\text { and accelerates their recovery through patient education. }\end{array}$ \\
\hline 34 & $\begin{array}{l}\text { Therapeutic communication is an important and required skill or technique to provide competent and empathic } \\
\text { psychological healthcare which can be taught through effective feedback. }\end{array}$ \\
\hline 61 & $\begin{array}{l}\text { The fundamental skill of therapeutic communication, which is developed through education, helps students deliver } \\
\text { patient education and care. }\end{array}$ \\
\hline 62 & $\begin{array}{l}\text { Therapeutic communication is a part of holistic and patient centered care which covers different aspects of physical } \\
\text { and psychological needs of patients through conveying information and making an interactive and relaxing } \\
\text { relationship with the nursing student. }\end{array}$ \\
\hline 63 & $\begin{array}{l}\text { Therapeutic communication, one of the most important forms of communication, is the foundation of professional } \\
\text { practice and a required and educable skill for exchanging information between patient and nursing student to help } \\
\text { patients overcome stress and adapt to unchangeable conditions. }\end{array}$ \\
\hline 64 & $\begin{array}{l}\text { Therapeutic communication skills, which can be developed through education and practice, are the most important } \\
\text { part of nursing. This process improves patient satisfaction through listening and conveying information. }\end{array}$ \\
\hline 65 & $\begin{array}{l}\text { Nursing students need to acquire necessary skills of therapeutic communication through training and evaluation } \\
\text { before engaging with patients. }\end{array}$ \\
\hline
\end{tabular}


Table 2. Nursing student-patient therapeutic communication defining attributes with their related items of Rosenberg \& Gallo-Silver instrument (29)

\begin{tabular}{|l|l|}
\hline Defining Attributes & Related items \\
\hline $\begin{array}{l}\text { An important means in building interpersonal } \\
\text { relationships }\end{array}$ & Introducing self to patient using names. \\
\hline A process of information transmission & Provides information to patient about the procedure. \\
\hline An important clinical competency & $\begin{array}{l}\text { Has adequate knowledge for answering patients' questions as completely } \\
\text { as possible. }\end{array}$ \\
\cline { 2 - 2 } & Acknowledges patient's concerns and feelings \\
\cline { 2 - 2 } & Explains routines of the hospital. \\
\hline A structure with two different sections & Uses body language such as nodding, leaning forward, etc. \\
\cline { 2 - 2 } & Uses open ended questions. \\
\hline A significant tool in patient centered care & Adapts interaction according to patients' responses and affect. \\
\hline
\end{tabular}

\section{Discussion}

Due to poor nursing student-patient encounters, researchers suggested that nursing authorities, having the mission of improving health of the community, should incorporate therapeutic communication as a key element in nursing education curriculum to improve students' therapeutic communication with patients $(19,64)$. In this concept analysis study, various studies regarding therapeutic communication between nursing student and patient were explored and the different attributes, antecedents and consequences of the concept were determined to shed more light on this concept and define it for wider practical application in nursing education and practice (40). Although the Walker and Avant method has been criticized as a simple linear positivist approach (69), this method is used as a systematic approach which is useful in disambiguation of complicated concepts (70). The first defining attribute of therapeutic communication was "an important means in building interpersonal relationships". Although therapeutic communication is a social interaction, it is different from it, as both partners do not have a balanced role in establishing and keeping the relationship $(7,8,12)$. Nurses or nursing students take the communication responsibility, accept and respect patients based on professional standards to care for the patient $(11,26)$. The second defining attribute of the concept was "a process of information transmission". Unlike the traditional communication theories which stress on rigid models (sender, message, channel and receiver), medical researchers believe that communication is a dynamic and context based information exchange process and they emphasize on the role of providing feedback in understanding the real meaning of the message in interaction $(15,17,19)$. Also, some other authors wrote that the nature of interaction varies based on people's visions, expectations, feelings and affections and nursing students should have flexibility to handle bad tempered patients $(7,8,21)$. The third defining attribute of therapeutic communication was "an important clinical competency". Researchers noted that nursing students' therapeutic communication competency encompasses knowledge, motivation and performance. These three elements should be considered together in effective therapeutic communication education and evaluation. Having a high level of therapeutic communication knowledge is essential as well as having a good attitude to apply it in performance $(18,20)$. The fourth defining characteristic of therapeutic communication was "a structure with two different sections" consisting of two different parts: verbal and nonverbal communication. Nursing students earn patients' trust through right words and tone of voice in verbal communication in order to assess patients' needs (14, 17, 38). Nonverbal communication (gaiting, appearance and eye contact) is another fundamental component in therapeutic communication and has an important role in the multi-lingual Iranian population, especially in old and illiterate patients who cannot understand Farsi or use written communication $(14,17,35,38)$. The fifth defining characteristic of therapeutic communication was "a significant tool in patient centered care". Patient education is suggested to empower patients and involve them in treatment and the self-care process in modern approaches to nursing care $(8,36)$. The vital component of patient education is therapeutic communication $(60,61)$. So, based on patient centered care approach, it is necessary for nurses and nursing students to communicate with their patients to prepare them to care for themselves $(10,42)$. Also, patients' needs and preferences are strongly considered and quality of care improves $(11,13,29)$. In the present study, the model borderline and negative cases are presented to open and illustrate this concept. Then, therapeutic communication antecedents were determined. Listening and giving feedback forms more than $75 \%$ of the therapeutic communication process (19-20). Although it is essential to assess patients' level of education for using appropriate words according to patient health literacy, asking patients some questions and giving them feedback at the end of interaction is also very important to ensure patient understanding $(19,20,27,29)$. Accepting patients with different cultures and characteristics and showing empathy towards them while respecting interpersonal boundaries play an important role in prevention of possible abuse of patients and leads to continuity of care and therefore, it is suggested by some researchers $(8,20,27-29)$. Therapeutic 
communication outcomes for patients include increasing patients' self-care knowledge and ability to satisfy their different physical needs and provide a more rapid healing process (14, 45, 59, 60, 62). Also, therapeutic communication has various psychological advantages for patients including building an effective emotional relationship with the nursing student, decreasing patient anxiety and stress, and improving patient safety and satisfaction $(15,18,19,36,45,46,51,62-64)$. Furthermore, therapeutic communication has positive benefits for nursing students. Nursing students communicate with patients to achieve their academic goals and do their assignments such as taking patients' history, doing physical exam and providing patient education. Moreover, the established interactions during these tasks have a profound effect on professional development of nursing trainees $(15,63)$. Non-Iranian researchers used simulation techniques $(32,34,44,50,55,57,59,61,62,67,68)$ and standardized patients $(7,52,58,65)$ to improve therapeutic communication in nursing trainees. Although Iranian researchers used portfolio and narrative writing in some studies $(64,66)$, these methods are not popular in the nursing education curriculum, and theoretical lectures are used to teach student nurses and clinical nurses regarding therapeutic communication $(14,46,60)$. Therefore, adopting theses new and student centered teaching methods is recommended to develop therapeutic communication skills in nursing students in a safe environment before entering clinical setting $(52,61)$.

\section{Conclusions}

The researchers integrated all the findings and concluded that therapeutic communication is the purposeful, interpersonal information transmitting process through words and behaviors based on both parties' knowledge, attitudes and skills which leads to patient understanding and participation. These findings may be used by the relevant authorities and nursing professors as the basics for developing evidence-based interventions to improve nursing students' therapeutic communication with patients in order to prepare them to work based on ethical communication principles contained in the charter of patient rights in the future. However, this study has a limitation. Researchers investigated studies in just six English and Persian databases. Therefore, conducting wider search in other databases such as CINAHL or Scientific Information Database (SID) is recommended in order to provide a more comprehensive definition of this concept.

\section{Acknowledgments:}

This research was a section of $\mathrm{PhD}$ thesis conducted through a grant from Tehran University of Medical Sciences.

\section{Conflict of Interest:}

There is no conflict of interest to be declared.

Authors' contributions:

All authors contributed to this project and article equally. All authors read and approved the final manuscript.

\section{References:}

1) Faden RR, Kass NE, Goodman SN, Pronovost P, Tunis S, Beauchamp TL. An ethics framework for a learning health care system: A departure from traditional research ethics and clinical ethics. Hastings Cent Rep. 2013; Spec No: S16-27. doi: 10.1002/hast.134. PMID: 23315888.

2) Purtilo RB, Haddad AM, Doherty RF. Health professional and patient interaction. 8 th ed. St. Louis: Elsevier; 2014.

3) Lin YH, Li J, Shieh SI, Kao CC, Lee I, Hung SL. Comparison of professional values between nursing students in Taiwan and China. Nurs Ethics. 2016; 23)2): 223-30. doi: 10.1177/0969733014561912. PMID: 25527355.

4) School of Nursing and Midwifery, Tehran Uinversity of Medical Sciences. Notification codes and ethics of nursing schools. 2016. Available From: http://fnm.tums.ac.ir/post/detail/Fa/2-120-4123640/ethicalcodesannouncment.aspx. Accessed Oct 122016.

5) Johnston J, Fidelia L, Robinson KW, Killion JB, Behrens P. An instrument for assessing communication skills of healthcare and human services students. Internet J Allied Health Sci Pract. 2011; 10(4): 1-6.

6) Karolak H. Philosophy of communication ethics: Scholarship beyond the one and the other. Rev Comm. 2015; 15(4): 316-31. doi: 10.1080/15358593.2015.1114138.

7) Sherko E, Sotiri E, Lika E. Therapeutic communication. JAHR-European Journal of Bioethics. 2013; 4(7): 457-66.

8) Kourkouta L, Papathanasiou IV. Communication in nursing practice. Mater Sociomed. 2014; $26(1): 65-7$. doi: 10.5455/msm.2014.26.65-67. PMID: 24757408, PMCID: PMC3990376. 
9) Berman A, Snyder S, Frandsen G. Kozier \& Erb's fundamentals of nursing: Concepts, practice, and process. 10th ed. Boston: Pearson; 2015.

10) Henry-Newton SG, Einstein GP, Tulp OL. The formulation of a patient-centered quality care improvement tool for nursing home patients. FASEB J. 2016; 30(1 Supplement): 674-42.

11) Parsapoor AR, Salari P, Larijani B. Implementation of patient's rights charter: A report from Ministry of Health and Medical Education, Iran. Iran J Public Health. 2013; 42(Supple1): 9-12. PMID: 23865009, PMCID: PMC3712606.

12) Birks M, Chapman Y, Davis J. Professional and therapeutic communication. South Melbourne, Vic: Oxford University Press; 2015.

13) Aled J. Putting practice into teaching: An exploratory study of nursing undergraduates' interpersonal skills and the effects of using empirical data as a teaching and learning resource. J Clin Nurs. 2007; 16(12): 2297307. doi: 10.1111/j.1365-2702.2007.01948.x. PMID: 18036120.

14) Baghcheghi N, Koohestani HR, Rezaei K. A comparison of the cooperative learning and traditional learning methods in theory classes on nursing students' communication skill with patients at clinical settings. Nurse Educ Today. 2011; 31(8): 877-82. doi: 10.1016/j.nedt.2011.01.006. PMID: 21288608.

15) Xie J, Ding S, Wang C, Liu A. An evaluation of nursing students' communication ability during practical clinical training. Nurse Educ Today. 2013; 33(8): 823-7. doi:10.1016/j.nedt.2012.02.011. PMID: 22417661.

16) Waters A, Whyte A. 'Nurses have a duty to be kind, friendly and polite'. Nurs Stand. 2012; 26(23): 16-8. doi: 10.7748/ns2012.02.26.23.16.p7488. PMID: 22413680.

17) Klakovich MD, Dela Cruz FA. Validating the interpersonal communication assessment scale. J Prof Nurs. 2006; 22(1): 60-7.doi: 10.1016/j.profnurs.2005.12.005. PMID: 16459290.

18) Jouzi M, Vanaki Z, Mohammadi E. Factors affecting the communication competence in Iranian nursing students: A qualitative study. Iran Red Crescent Med J. 2015; 17(3): e19660. doi: 10.5812/ircmj.19660. eCollection 2015. PMID: 26019902, PMCID: PMC4441787.

19) Shafakhah M, Zarshenas L, Sharif F, Sabet Sarvestani R. Evaluation of nursing students' communication abilities in clinical courses in hospitals. Glob J Health Sci. 2015; 7(4): 323-8. doi: 10.5539/gjhs.v7n4p323. PMID: 25946924, PMCID: PMC4802203.

20) Wloszczak-Subzda A, Jarosz MJ. Professional communication competences of nurses. Ann Agric Environ Med. 2012; 19(3): 601-7. PMID: 23020064.

21) Heidari $\mathrm{H}$, Mardani Hamooleh $\mathrm{M}$. Improving communication skills in clinical education of nursing students. Client-Centered Nursing Care. 2015; 1(2): 77-82.

22) Sheldon LK, Hilaire DM. Development of communication skills in healthcare: Perspectives of new graduates of undergraduate nursing education. J Nurs Educ Pract. 2015; 5(7): 30-7. doi: 10.5430/jnep.v5n7p30.

23) Zamanzadeh V, Rassouli M, Abbaszadeh A, Nikanfar A, Alavi-Majd H, Ghahramanian A. Factors influencing communication between the patients with cancer and their nurses in oncology wards. Indian J Palliat Care. 2014; 20(1): 12-20. doi: 10.4103/0973-1075.125549. PMID: 24600177, PMCID: PMC3931236.

24) Cowen KJ, Hubbard LJ, Hancock DC. Concerns of nursing students beginning clinical courses: A descriptive study. Nurse Educ Today. 2016; 43: 64-8. doi: 10.1016/j.nedt.2016.05.001. PMID: 27286947.

25) Ma F, Li J, Liang H, Bai Y, Song J. Baccalaureate nursing students' perspectives on learning about caring in China: A qualitative descriptive study. BMC Med Educ. 2014; 14: 42. doi: 10.1186/1472-6920-14-42. PMID: 24589087, PMCID: PMC3944811.

26) Mullan BA, Kothe EJ. Evaluating a nursing communication skills training course: The relationships between self-rated ability, satisfaction, and actual performance. Nurse Educ Pract. 2010; 10(6): 374-8. doi: 10.1016/j.nepr.2010.05.007. PMID: 20541974.

27) Jirwe M, Gerrish K, Emami A. Student nurses' experiences of communication in cross - cultural care encounters. Scand J Caring Sci. 2010; 24(3): 436-44. doi: 10.1111/j.1471-6712.2009.00733.x. PMID: 20233352.

28) McMillan LR, Shannon DM. Psychometric analysis of the JSPE nursing student version R: Comparison of senior BSN students and medical students attitudes toward empathy in patient care. ISRN Nurs. 2011; 2011: 726063. doi: 10.5402/2011/726063. PMID: 21994895, PMCID: PMC3169335.

29) Rosenberg S, Gallo-Silver L. Therapeutic communication skills and student nurses in the clinical setting. Teaching and Learning in Nursing. 2011; 6(1): 2-8. doi: 10.1016/j.teln.2010.05.003. 
30) MacDonald-Wicks L, Levett-Jones T. Effective teaching of communication to health professional undergraduate and postgraduate students: A Systematic Review. JBI Libr Syst Rev. 2012; 10 (28 Suppl): 1 12. doi: 10.11124/jbisrir-2012-327. PMID: 27820404.

31) Jvaher AA, Khaghanizadeh M, Ebadi A. Study of communication skills in nursing students and its association with demographic characteristics. Iranian Journal of Medical Education. 2014; 14(1): 23-31.

32) Szpak JL, Kameg KM. Simulation decreases nursing student anxiety prior to communication with mentally ill patients. Clin Simul Nurs. 2013; 9(1): e13-9. doi:10.1016/j.ecns.2011.07.003.

33) Emmanuel E, Collins D, Carey M. My face, a window to communication: Using creative design in learning. Nurse Educ Today. 2010; 30(8): 720-5. doi:10.1016/j.nedt.2010.01.011. PMID: 20149503.

34) Miles LW, Mabey L, Leggett S, Stansfield K. Teaching communication and therapeutic relationship skills to baccalaureate nursing students: A peer mentorship simulation approach. J Psychosoc Nurs Ment Health Serv. 2014; 52(10): 34-41. doi: 10.3928/02793695-20140829-01. PMID: 25207556.

35) Norouzinia R, Aghabarari M, Shiri M, Karimi M, Samami E. Communication barriers perceived by nurses and patients. Glob J Health Sci. 2015; 8(6): 65-74. doi: 10.5539/gjhs.v8n6p65. PMID: 26755475, PMCID: PMC4954910.

36) Campbell SH, Pagano MP, O'Shea ER, Connery C, Caron C. Development of the health communication assessment tool: Enhancing relationships, empowerment, and power-sharing skills. Clin Simul Nurs. 2013; 9(11): e543-e50. doi:10.1016/j.ecns.2013.04.016.

37) Figueiredo SV, Gomes ILV, Pennafort VPdS, Monteiro ARM, Figueiredo JV. Therapeutic communication between health professionals and mothers accompanying children during inpatient treatment. Esc Anna Nery. 2013; 17(4): 690-7. doi: 10.5935/1414-8145.20130013.

38) McDonald M. The nurse educator's guide to assessing learning outcomes. 3ed. Burlington, MA: Jones \& Bartlett Learning; 2014.

39) Grant MS, Jenkins LS. Communication education for pre-licensure nursing students: Literature review 2002-2013. Nurs Educ Today. 2014; 34(11): 1375-81. doi: 10.1016/j.nedt.2014.07.009. PMID: 25151020.

40) Walker LO, Avant KC. Strategies for theory construction in nursing. 5th ed. Boston: Prentice Hall; 2011.

41) Jones T, Shaban RZ, Creedy DK. Practice standards for emergency nursing: An international review. Australas Emerg Nurs J. 2015; 18(4): 190-203. doi: 10.1016/j.aenj.2015.08.002. PMID: 26440608.

42) Hess EP, Grudzen CR, Thomson R, Raja AS, Carpenter CR. Shared decision-making in the emergency department: Respecting patient autonomy when seconds count. Acad Emerg Med. 2015; 22(7): 856-64. doi: 10.1111/acem.12703. PMID: 26112797.

43) Gifu D, Dima IC, Teodorescu M. New communication approaches vs. traditional communication. International Letters of Social and Humanistic Sciences. 2014; (31): 46-55. doi: 10.18052/www.scipress.com/ILSHS.31.46.

44) Walker D, Ross JM. Therapeutic computing: Teaching therapeutic communications utilizing a videodisc. Comput Nurs. 1995; 13(3): 103-8. PMID: 7796366.

45) Hayes A. A mental health nursing clinical experience with hospice patients. Nurse Educ. 2005; 30(2): 85-8. PMID: 15785347.

46) Sadat Manzari Z, Memarian R, Vanaki Z. The effect of implementing therapeutic communication plan on burned patients' pain. ZUMS. 2006; 14(54): 10-16.

47) Becker KL, Rose LE, Berg JB, Park H, Shatzer JH. The teaching effectiveness of standardized patients. J Nurs Educ. 2006; 45(4): 103-11. PMID: 16629278.

48) McNeill C, Shattell M, Rossen E, Bartlett R. Relationship skills building with older adults. J Nurs Educ. 2008; 47(6): 269-71. doi: 10.3928/01484834-20080601-07. PMID: 18557314.

49) Weissman GV. Evaluating associate degree nursing students' self-efficacy in communication skills and attitudes in caring for the dying patient. Teaching and Learning in Nursing. 2011; 6(2): 64-72. doi: 10.1016/j.teln.2010.10.004.

50) Suplee PD, Solecki SM. Creating and implementing pediatric simulation experiences for licensed practical nursing students. Clin Simul Nurs. 2011; 7(4): e127-32. doi: 10.1016/j.ecns.2010.01.001.

51) Damasceno MM, Zanetti ML, de Carvalho EC, Teixeira CR, de Araújo MF, Alencar AM. Therapeutic communication between health workers and patients concerning diabetes mellitus care. Rev Lat Am Enfermagem. 2012; 20(4): 685-92. doi: 10.1590/S0104-11692012000400008. PMID: 22990153.

52) Webster D, Seldomridge L, Rockelli L. Making it real: Using standardized patients to bring case studies to life. J Psychosoc Nurs Ment Health Serv. 2012; 50(5): 36-41. doi: 10.3928/02793695-20120410-06. PMID: 22533843. 
53) Leef BL, Hallas D. The sensitivity training clown workshop: Enhancing therapeutic communication skills in nursing students. Nurs Educ Perspect. 2013; 34(4): 260-4. doi: 10.5480/1536-5026-34.4.260. PMID: 24187731 .

54) Grossman S. Development of the palliative care of dying critically ill patients algorithm: Implications for critical care nurses. J Hosp Palliat Nurs. 2013; 15(6): 355-9. doi: 10.1097/NJH.0b013e3182987b1c.

55) McAllister M, Levett-Jones T, Downer T, Harrison P, Harvey T, Reid-Searl K, et al. Snapshots of simulation: Creative strategies used by Australian educators to enhance simulation learning experiences for nursing students. Nurse Educ Pract. 2013; 13(6): 567-72. doi: 10.1016/j.nepr.2013.04.010. PMID: 23707534.

56) Taylor EJ, Mamier I. Nurse responses to patient expressions of spiritual distress. Holist Nurs Pract. 2013; 27(4): 217-24. doi: 10.1097/HNP.0b013e318294e50a. PMID: 23774721.

57) Spinner-Gelfars AH. Using simulation to promote effective communication with a diverse student population. Teaching and Learning in Nursing. 2013; 8(3): 96-101. doi:10.1016/j.teln.2013.01.004.

58) Webster D. Using standardized patients to teach therapeutic communication in psychiatric nursing. Clin Simul Nurs. 2014; 10(2): e81-6. doi: 10.1016/j.ecns.2013.08.005.

59) Mawson K. Use of media technology to enhance the learning of student nurses in regards to auditory hallucinations. Int J Ment Health Nurs. 2014; 23(2): 135-44. doi: 10.1111/inm.12031. PMID: 23755742.

60) Sadat Manzari Z, Memarian R, Vanaki Z. Effectiveness of therapeutic communication program based on Hilgard Peplau theory on burned patient's participation in caring and curing plans. Journal of Ethics and Culture in Nursing and Midwifery. 2014; 1(1): 35-46.

61) Rossetti J, Musker K, Smyth S, Byrne E, Maney C, Selig K, et al. Creating a simulated mental health ward: Lessons learned. J Psychosoc Nurs Ment Health serv. 2014; 52(10): 52-8. doi: 10.3928/0279369520140903-02. PMID:25207558.

62) Martin CT, Chanda N. Mental health clinical simulation: Therapeutic communication. Clin Simul Nurs. 2016; 12(6): 209-14. doi: 10.1016/j.ecns.2016.02.007.

63) Yas MI, Mohammed SH. Assessment of nurses knowledge about therapeutic communication in psychiatric teaching hospitals at Baghdad City. Kufa Journal for Nursing Sciences. 2016; 6(2): 1-7.

64) Moghadami A, Jouybari L, Baradaran HR, Sanagoo A. The effect of narrative writing on communication skills of nursing students. Iranian Journal of Medical Education. 2016; 16: 149-156.

65) Jacobs AC, van Jaarsveldt DE. 'The character rests heavily within me': Drama students as standardized patients in mental health nursing education. J Psychiatr Ment Health Nurs. 2016; 23(3-4): 198-206. doi: 10.1111/jpm.12302. PMID: 27090349.

66) Vaghee S, Salarhaji A, Karimi Moonaghi H, Soadatjo SAR, Banezhad A. Effect of portfolio application on satisfaction and educational achievement of nursing students in psychiatry clerkship. J Med Edu Dev. 2016; 9(23): 112-21.

67) Liebrecht C, Montenery S. Use of simulated psychosocial role-playing to enhance nursing students' development of soft skills. Creat Nurs. 2016; 22(3): 171-5. doi: 10.1891/1078-4535.22.3.171.

68) Ross JG, Bruderle E, Meakim CH, Willens JS, Holmwood JA. Development of formative capstone simulations to prepare novice students for initial clinical practicum. J Nurs Educ. 2016; 55(10): 587-9. doi: 10.3928/01484834-20160914-09. PMID: 27668740.

69) Draper P. A critique of concept analysis. J Adv Nurs. 2014; 70(6): 1207-8. doi: 10.1111/jan.12280. PMID: 24467340.

70) Knafl KA, Deatrick JA. Commentary on: Draper P. (2014) Editorial: a critique of concept analysis. Journal of Advanced Nursing 70, 1207-1208. J Adv Nurs. 2014; 70(12): 2968. doi: 10.1111/jan.12465. PMID: 25378184. 